Research Article

\title{
Optimal Control of Semiactive Two-Stage Vibration Isolation Systems for Marine Engines
}

\author{
YuanYuan Fang (iD \\ School of Energy and Power, Jiangsu University of Science and Technology, Zhenjiang 212003, China \\ Correspondence should be addressed to YuanYuan Fang; fangyy82@163.com
}

Received 14 June 2021; Revised 13 July 2021; Accepted 26 July 2021; Published 3 August 2021

Academic Editor: N. A. Saeed

Copyright (c) 2021 Yuanyuan Fang. This is an open access article distributed under the Creative Commons Attribution License, which permits unrestricted use, distribution, and reproduction in any medium, provided the original work is properly cited.

To improve the vibration reduction performance of two-stage vibration isolation systems for marine engines under wide frequency band and multifrequency excitation, the magnetorheological (MR) damper is introduced into the vibration isolation system and an optimal controller is designed. Taking the test results of MR damper dynamic characteristics as sample data, the forward and inverse models of the MR damper are identified by the least square method and neural network (NN) method respectively, and the identification results are applied to semiactive control of the two-stage isolation system. Based on the analysis of vibration source, a six-degree-of-freedom mechanical model of two-stage system based on the MR damper is established. The optimal controller taking the minimum force transmitted from the engine to base as the control objective is designed. The system model and numerical simulation analysis are established using MATLAB. The results show that the isolation effect of optimal control is better than that of passive vibration isolation in the whole frequency band. In addition, good control effect is achieved in the low-frequency resonance region which is most concerned in engineering, which is of great significance to further improve the vibration reduction performance of marine engines.

\section{Introduction}

The vibration and noise generated during the operation of power equipment may bring serious harm to equipment safety and external environment [1]. Vibration isolation is one of the important means to reduce the vibration and noise of mechanical equipment $[2,3]$. The design of excellent vibration isolation systems for equipment can improve the comfort of the crew and reduce the radiated noise of the ship. At present, passive vibration isolation technology is usually used in vibration isolation systems, which has simple structure but limited effect. In contrast, the active vibration isolation system utilizing actuator equipment can provide good isolation performance but require big power supply and sophisticated control implementation.

The semiactive control system can improve the vibration isolation performance and reduce the external energy supply $[4,5]$. The semiactive control based on MR material has the advantages of low energy consumption, fast response, simple structure, and good reliability. The MR dampers and MR absorbers based on MR material have been developed as controllable isolation devices installed in the engines for vibration alleviation and mitigation [6]. MR material technology and devices are presented, and many MRE-based isolators have been numerically and experimentally researched [7]. Yuan et al. [8] introduced technical characteristics, comprehensive performance, and developing trend and their dependencies on structures of different types of MR dampers. The MR dampers have been employed by Zhao et al. in a cable-stayed bridge to mitigate rain-wind induced vibration [9]. Yu et al. [10] proposed a rotating hysteresis model which consists of rotating spring, rotating viscous damping element, and hysteresis element based on error function, and this device with variable stiffness model can reduce the rotational oscillation. Zhang et al. [11] studied the nonlinear and hysteretic characteristics of MR dampers used to suppress the vibration transmission of automobile seat suspension.

It is advantageous to introduce nonlinearity into the vibration isolation system. Moreover, damping nonlinearity 
is considered to be introduced first. Nonlinear MR dampers have more obvious vibration reduction effect on the resonance region than on the vibration isolation region [12]. The two-stage vibration isolation system in this paper has a good effect on the vibration isolation region. In order to further improve the resonance response of the system, a semiactive MR damper is introduced to reduce the main resonance characteristics of the system. So far, more and more attention has been paid to the dynamic modeling and semiactive vibration control of MR dampers, but the research of semiactive dynamic mechanical vibration isolation technology based on forward and inverse mechanical models of the MR damper needs further exploration.

Damping force of the MR damper can be calculated accurately by the forward dynamic model according to the vibration state and current, so the establishment of accurate forward model is an important prerequisite for the application of MR dampers in engine vibration control. In order to characterize the performance of MR dampers, many scholars have proposed a variety of models to describe their mechanical behavior and applied them to semiactive control of engineering structures, such as Bingham viscoelastic model, polynomial model, Bouc-Wen model, and hysteresis model [13-16]. Among them, the hyperbolic tangent function model can smoothly simulate the double viscosity and hysteresis of MR dampers and can well reflect the dynamic characteristics of MR dampers under different vibration amplitudes. The model has high accuracy and simple mathematical expression, which is easily help identify and design the controller.

For the semiactive control of engine vibration, the output force of MR dampers cannot be controlled directly. We must control the current applied by the MR damper. That is to say, it is necessary to convert the required control force signal into current signal to adjust the output of $M R$ damper. The conversion of force signal and current signal can be achieved by using the inverse model of MR damper or using the algorithm that can convert the control force into current signal. Therefore, accurate inverse dynamic modeling is the premise of applying MR dampers to dynamic mechanical vibration control. Combined with efficient and good control strategy, the expected control effect can be achieved [17-19]. Compared with the forward dynamic modeling of MR dampers, the inverse dynamic modeling of MR damper is less reported. In order to ensure the effectiveness of the neural network inverse mechanical model, it is necessary to obtain rich dynamic response information which can cover the working range of the MR damper as training samples. Due to the limitation of loading excitation in the mechanical test, the forward model is selected as the sample data source for solving the reverse mechanical model. Next, based on the forward and reverse mechanical models of the MR damper, considering the current limitation of the MR damper, the control module is established and applied to the semiactive two-stage isolation system control.

About the semiactive control of two-stage vibration isolation system for marine engines, the vibration response of engines under vertical excitation force is usually studied and the influence of torque on isolation performance is often ignored [20]. In this paper, the forced vibration model of the two-stage semiactive vibration isolation system with the MR damper is established, which takes into account the inertial force, inertial moment, and pitch moment of marine engines. The dynamic equation of the two-stage vibration isolation system is obtained by the Lagrange method, and the semiactive optimal control of the isolation system is carried out by using the control module of the MR damper and the optimal control principle. The force transmitted from the isolation system to the base and the vibration displacement of the marine engine are obtained by simulation analysis. The force transmissibility of the two-stage vibration isolation system is calculated in the whole frequency band of the engine operation.

\section{Mechanical Model of the MR Damper}

2.1. Forward Mechanical Model. The key to control system vibration using the MR damper is to establish a simple and accurate mechanical model which can reflect the damping characteristics of MR dampers. Firstly, the material performance testing machine (MTS) is used to test the mechanical characteristics of a certain type of MR damper. The test system is shown in Figure 1. The damping force response data of the damper under different excitation parameters and control currents are collected for modeling the mechanical characteristics of the damper.

The excitation amplitude is $2 \mathrm{~mm}, 5 \mathrm{~mm}$, and $10 \mathrm{~mm}$, respectively, the frequency is $0.5 \mathrm{~Hz}, 1 \mathrm{~Hz}, 1.5 \mathrm{~Hz}$, and $2 \mathrm{~Hz}$, respectively, and the control current is $0 \mathrm{~A}, 0.5 \mathrm{~A}, 1 \mathrm{~A}, 1.5 \mathrm{~A}$, and $2 \mathrm{~A}$ respectively. The sampling frequency of test data is $200 \mathrm{~Hz}$, and the test is carried out under 60 working conditions. In the end, the piston displacement and output damping force signals are obtained and the damper velocity signal can be obtained by differential of displacement signal.

Hyperbolic tangent function and linear function composed of damping coefficient and elastic stiffness coefficient are used in combination to describe the dynamic characteristics of the MR damper. It is easy to identify parameters and simulate dynamic characteristics of the MR damper when the vibration amplitude changes. It has high accuracy and can be easily applied to the controller. The least square method is used for parameter identification. The comparison results of the fitting curves of damping force-displacement and damping force-velocity with the test curves are shown in Figure 2. The identified model expression is as follows:

$$
F_{M R}=q_{1} \tan h(0.094 *(v+0.986 x))+q_{2}(v+0.986 x),
$$

where

$$
\begin{aligned}
& q_{1}=528.6 * I+159.6, \\
& q_{2}=3.193 * I+2.807,
\end{aligned}
$$

where $F_{\mathrm{MR}}$ is the damping force of the MR damper, $v$ and $x$ are the relative velocity and displacement between the cylinder and piston, and $I$ is the control current of the MR damper. $q_{1}$ is the shear stress related to the control current 


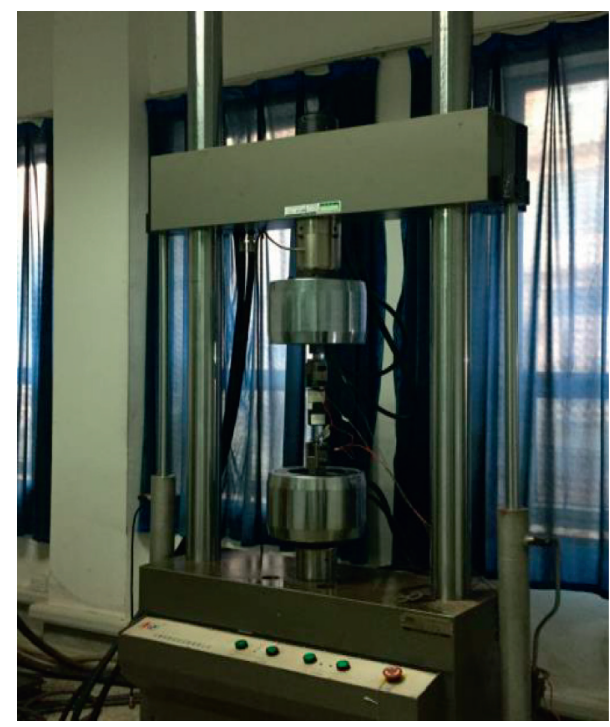

FIGURE 1: Testing system of mechanical performance of the MR damper.

and $q_{2}$ is the coefficient related to the damping in the yield region, $q_{2}=\left(V_{0} / X_{0}\right)\left(V_{0}\right.$ and $X_{0}$ are the crossing velocity and displacement when the damping force of the damper is equal to zero).

It can be found that the $F-x$ and $F-v$ curves are in good agreement. The mean square error of the predicted value of the hyperbolic tangent model is $4.41 \%$, which indicates that the model can accurately predict the damping force of the MR damper.

2.2. Inverse Mechanical Model. The neural network inverse mechanical model of the MR damper is used to calculate the required control current from the expected damping force. The inverse mechanical model can be obtained by reversederiving forward model or by using artificial NN. In this paper, backpropagation (BP) network is used to establish the mechanical inverse model of MR damper. The excitation of marine engines is usually periodic, which can be obtained by superposition of simple harmonic functions. In order to ensure the effectiveness of the inverse mechanical model, it is necessary to obtain rich dynamic response information which can cover the working range of the MR damper as training samples. In order to take the relationship between model accuracy and prediction time consumption into account, the displacement $x(t-1)$, velocity $\dot{x}(t-1)$, current $I(t-1)$, damping force $F(t-1)$ at last moment, displacement $x(t)$, velocity $\dot{x}(t)$, and damping force $F(t)$ at this moment are selected as the inputs of the inverse force model and the control current $I(t)$ at this moment is selected as the output. The layer number is three. Among them, there are 7 input layer nodes. Considering the error and training time, the number of hidden layer nodes is selected as 8 .

The neural network modeling data are shown in Table 1. Damping force can be obtained by the forward model. The data generated by the first three columns of displacement signals and current signals are selected as the training samples of the inverse model, and the data generated by the last column is used as the verification data. When the training reaches the expected accuracy, the BP inverse mechanical model is obtained.

In Table 1, CHIRP is a swept cosine signal with a frequency range of $5-50 \mathrm{~Hz}$ and a unit amplitude. The training data are modeled according to the above selected neural network model parameters. The amount of data for network training and validation have been chosen as 1500 and 500, respectively. Finally, the training error of BP neural network model is shown in Figure 3.

In order to improve the defects of BP such as slow convergence speed and easy to fall into local small value, genetic algorithm (GA) is used to optimize the weights and thresholds of inverse BP to improve the prediction accuracy of the model. In GA, chromosomes share information with each other, so the whole population moves evenly to the optimal region. The size of population selected is 50 , and the maximum evolution algebra is 200 . The selection of crossover probability is 0.8 , and the selection of mutation probability is 0.07 . The initial weights and thresholds are assigned by the optimal individuals obtained by genetic algorithm. Training error for the GA-BP model is shown in Figure 4 . The schematic diagram of GA-BP reverse dynamics modeling is shown in Figure 5. As can be observed in Figures 3 and 5, both the training errors are under 0.005 .

The fitness function $f(i)$ is defined as the root mean square error of current:

$$
f(i)=\sqrt{\frac{1}{n} \sum_{i=1}^{n}}\left(y_{i}-p_{i}\right)^{2},
$$

where $n$ is the number of output nodes for neural network, $y_{i}$ is the actual output value of BP network, and $p_{i}$ is the expected value. The simulation analysis shows that the root mean square error of the BP model optimized by genetic algorithm is $2.3 \%$, and the comparison between the predicted current value and the target value of the inverse model is shown in Figure 6. We can observe the error between them as very small.

2.3. Control Module of the MR Damper. The limit of the electric current shows that the output force is a bounded value. The semiactive control force is between the damping force of the MR damper under zero current and the maximum current. In order to calculate the control current according to the inverse model, the expected control force of the vibration isolation system must be between the controllable force limits of the MR damper. Otherwise, the coil input current is specified as the extreme value.

Firstly, according to the vibration response of the system, the minimum and maximum values of the output damping force are calculated as the adjustable range. Then, according to the relationship between the ideal damping force required by the semiactive control system and the damping force provided by the MR damper, the current input to the damper is determined. The control module of MR damper is shown in Figure 7. 


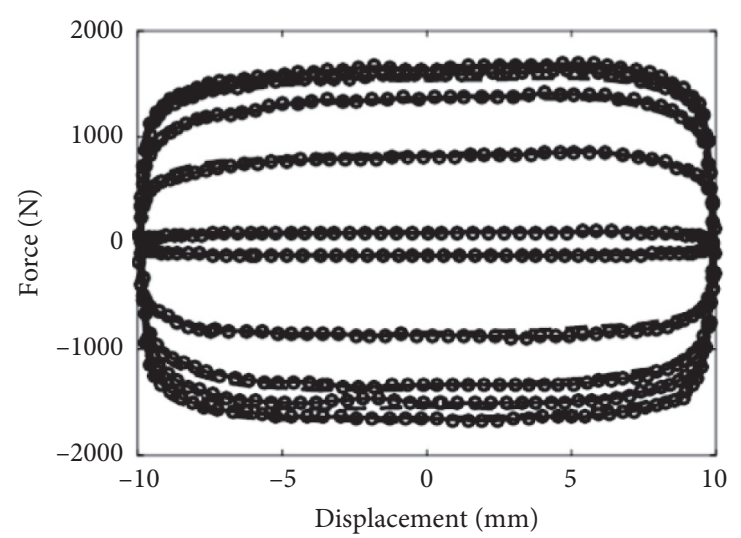

(a)

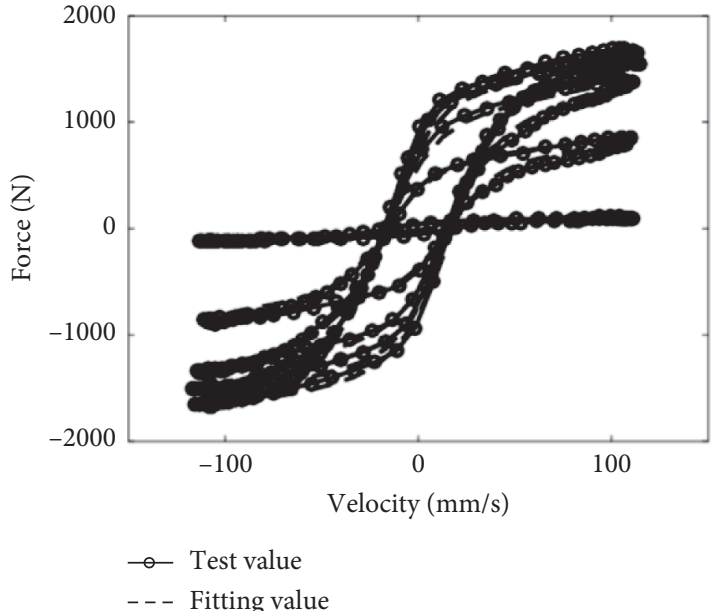

(b)

FIgURE 2: Comparison between predictions and experimental results.

TABLE 1: Modeling data of neural network.

\begin{tabular}{|c|c|c|c|c|}
\hline \multirow{2}{*}{ Signal } & \multicolumn{4}{|c|}{ Time (s) } \\
\hline & $0-8$ & $8-16$ & $16-23$ & $23-25$ \\
\hline Displacement & $2 \sin (20 \pi t)$ & $5 \sin (5 \pi t)+10 \sin (10 \pi t)$ & $8 \sin (2 \pi t)$ & $7 \sin (5 \pi t)$ \\
\hline Current & |CHIRP| & $|0.5 \sin (2 \pi t)+\sin (4 \pi t)|$ & 1.5 & $|\sin (4 \pi \mathrm{t})|$ \\
\hline
\end{tabular}

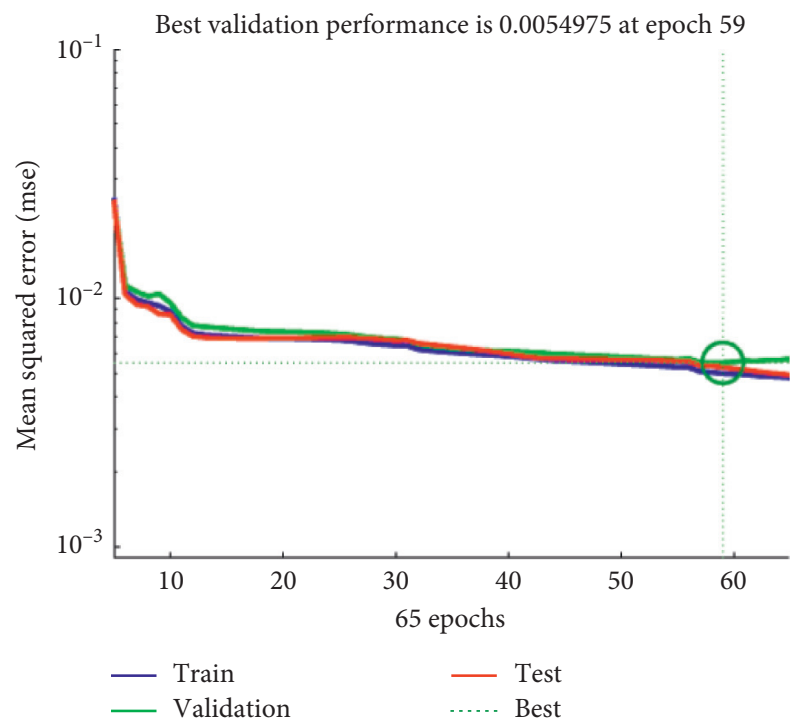

Figure 3: Training error of the BP network reverse model.

\section{Dynamic Model of the Two-Stage Semiactive Vibration Isolation System}

The establishment of the isolation system model is the premise of semiactive control, and it is also an important part of control system design.

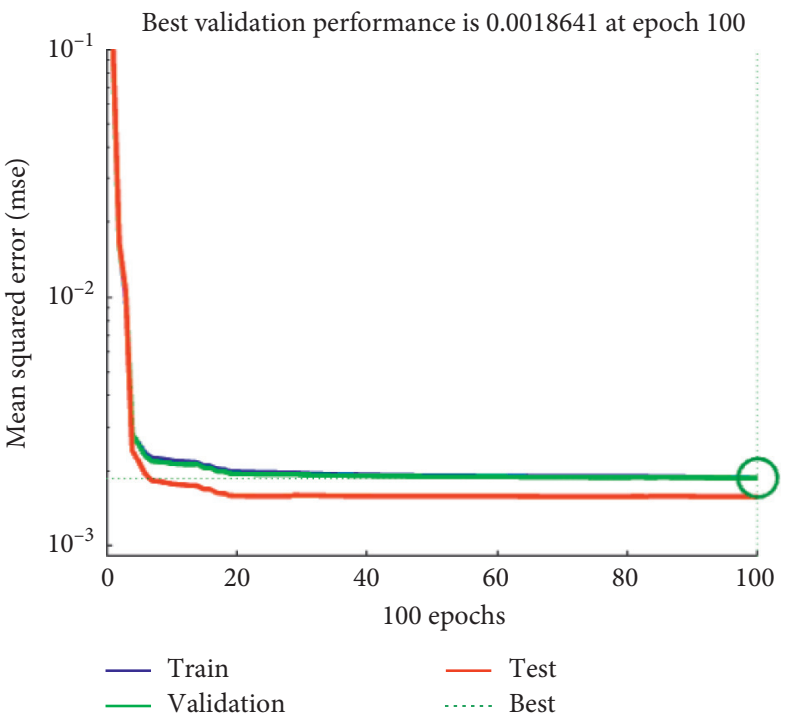

FIgure 4: Training error of the GA-BP network reverse model.

3.1. Excitation Characteristics of the Engine. Dynamic analysis of vibration source is vital for studying vibration control of the two-stage semiactive vibration isolation system. Taking a 4-cylinder 4-stroke in-line engine as the research object, its main excitation is the second-order torque fluctuation around the crankshaft ( $x$-axis) in the 


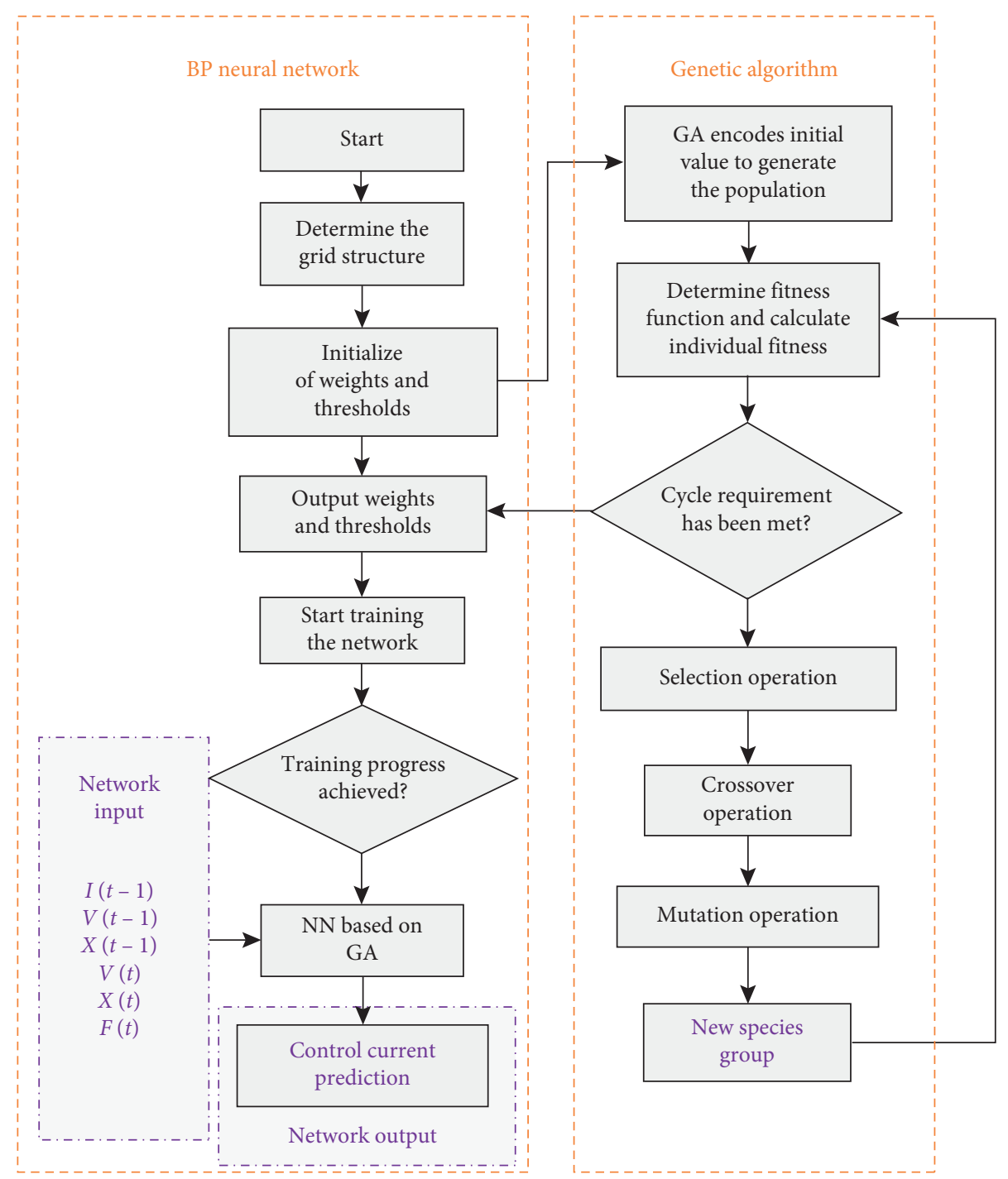

Figure 5: Schematic diagram of the GA-BP inverse dynamic model of the MR damper.

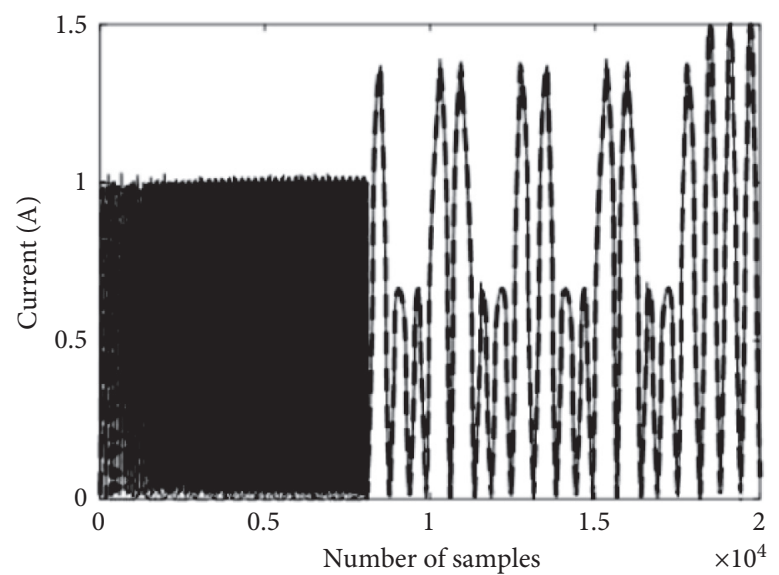

Figure 6: Comparison of current prediction value and target value. Solid line: target value; dashed line: prediction value.

low-frequency band and the second-order reciprocating inertia force along the vertical ( $Y$-axis) direction in the high-frequency band. The exciting force of the whole cylinder block is a space force system composed of the exciting force of each single cylinder according to different ignition sequences.

The second-order inertial force in the vertical direction is as follows: 


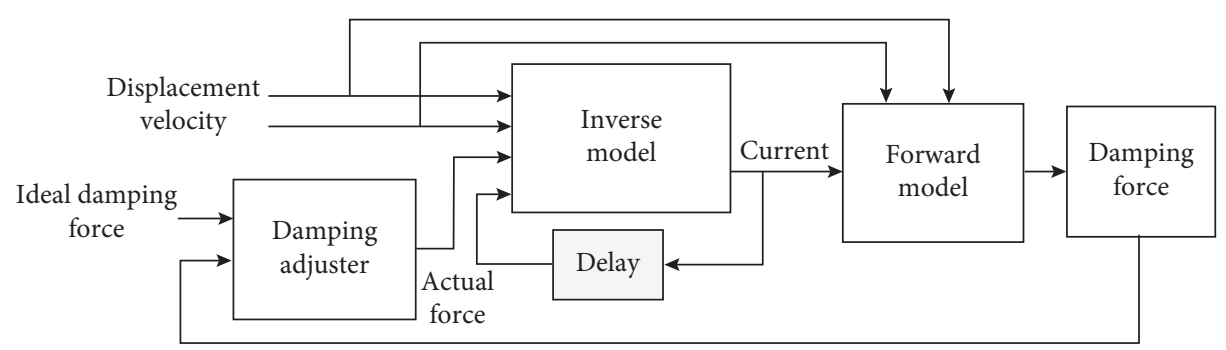

Figure 7: The control module of the MR damper.

$$
\sum F_{y}=4 m_{c} r \lambda \omega^{2} \cos (2 \omega t) .
$$

The longitudinal rolling moment around the engine (in the direction of output shaft) is

$$
\sum M_{x} \approx M_{e 0}(1+1.3 \sin (2 \omega t))
$$

where $M_{e 0}$ is the average value of engine output torque.

The pitch moment is

$$
M_{z}=F_{y} A=\left(m_{c} r \omega^{2}+m_{r} r \omega^{2}\right) L \cos (2 \omega t) .
$$

3.2. Dynamic Modeling of the Vibration Isolation System. The vertical vibration, pitch motion, and roll motion around the output shaft of the engine are considered, and other motions are ignored. The mass of the engine is $m_{e}$. The mass of the intermediate mass is $m_{m}$. The moment of inertia around the $X$ and $Y$ axes is recorded as $I_{x}$ and $I_{y}$, respectively. The dynamic model of the two-stage semiactive isolation system and the layout of each stage of vibration isolator relative to the supporting structure are shown in Figure 8. In these rectangular coordinates, the $X$-axis is parallel to the crankshaft, the $Y$-axis is perpendicular to the crankshaft, and the $Z$-axis is perpendicular to the base plane.

Generally, the first natural frequencies of the engine and the intermediate mass are above tens of Hertz, which can be regarded as rigid bodies with six degrees of freedom, respectively. For the two-stage vibration isolation system with horizontal arrangement, the main goal of semiactive control is to suppress the vertical vibration mode of the engine and coupling of modes in three directions. According to the position of the vibration isolator, the relationship between the displacement $y_{j}$ of the vibration isolator and each degree of freedom $q_{i}$ of the two-stage vibration isolation system can be obtained:

$$
\begin{aligned}
& \left\{\begin{array}{l}
y_{1 e} \\
y_{2 e} \\
y_{3 e} \\
y_{4 e}
\end{array}\right\}=\left[\begin{array}{cccccc}
1 & -d_{r} & d_{f} & -1 & l_{r} & -l_{f} \\
1 & d_{l} & d_{f} & -1 & -l_{l} & -l_{f} \\
1 & d_{l} & -d_{b} & -1 & -l_{l} & l_{b} \\
1 & -d_{r} & -d_{b} & -1 & l_{r} & l_{b}
\end{array}\right]\left\{\begin{array}{l}
y_{e} \\
\theta_{e} \\
\varphi_{e} \\
y_{m} \\
\theta_{m} \\
\varphi_{m}
\end{array}\right\}, \\
& \left\{\begin{array}{l}
y_{1 m} \\
y_{2 m} \\
y_{3 m} \\
y_{4 m}
\end{array}\right\}=\left[\begin{array}{ccc}
1 & -l_{r} & l_{f} \\
1 & l_{l} & l_{f} \\
1 & l_{l} & -l_{b} \\
1 & -l_{r} & -l_{b}
\end{array}\right]\left\{\begin{array}{c}
y_{m} \\
\theta_{m} \\
\varphi_{m}
\end{array}\right\},
\end{aligned}
$$

where $\mathbf{q}_{\mathbf{i}}=\left\{y_{e}, \theta_{e}, \varphi_{e}, y_{m}, \theta_{m}, \varphi_{m}\right\}$.
According to Lagrange equation

$$
\frac{\mathrm{d}}{\mathrm{d} t}\left(\frac{\partial \mathbf{T}}{\partial \dot{q}_{\mathbf{i}}}\right)-\frac{\partial \mathbf{T}}{\partial \mathbf{q}_{\mathbf{i}}}+\frac{\partial \mathbf{V}}{\partial \mathbf{q}_{\mathbf{i}}}+\frac{\partial \mathbf{R}}{\partial \dot{q}_{\mathbf{i}}}=\mathbf{Q}_{\mathbf{i}},
$$

the dynamic equation of the two-stage isolation system can be obtained:

$$
[\mathbf{M}] \ddot{q}+[\mathbf{C}] \dot{q}+[\mathbf{K}] q=\mathbf{b}_{2} \mathbf{w}
$$

where $\mathbf{w}$ is the motivation of the engine, $\mathbf{w}=\left[F_{y}, M_{\theta}, M_{\varphi}\right]^{T}$, and $F_{y}, M_{\theta}$, and $M_{\varphi}$ represent the vertical unbalanced force, horizontal rolling moment, and pitch moment of engine, respectively. The control force of the MR damper is introduced into the passive vibration isolation device, and $f_{1}, f_{2}, f_{3}$, and $f_{4}$ are used to represent the control force of four MR dampers. The dynamic equation of the semiactive vibration isolation system is as follows:

$$
[\mathbf{M}] \ddot{q}+[\mathbf{C}] \dot{q}+[\mathbf{K}] q=\mathbf{b}_{1} \mathbf{u}+\mathbf{b}_{2} \mathbf{w},
$$

where

$$
\begin{aligned}
& u=\left[f_{1}, f_{2}, f_{3}, f_{4}\right]^{T}, \\
& b_{1}=\left[\begin{array}{rrrr}
1 & 1 & 1 & 1 \\
-d_{r} & d_{l} & d_{l} & -d_{r} \\
d_{f} & d_{f} & -d_{b} & -d_{b} \\
1 & 1 & 1 & 1 \\
-l_{r} & l_{l} & l_{l} & -l_{r} \\
l_{f} & l_{f} & -l_{b} & -l_{b}
\end{array}\right], \\
& b_{2}=\left[\begin{array}{lll}
1 & 0 & 0 \\
0 & 1 & 0 \\
0 & 0 & 1 \\
0 & 0 & 0 \\
0 & 0 & 0 \\
0 & 0 & 0
\end{array}\right] .
\end{aligned}
$$

\section{Optimal Control of the Semiactive Vibration Isolation System}

The design of control strategy is very important for semiactive vibration control. Optimal control, fuzzy control, PID control, and adaptive control are commonly used. In order 

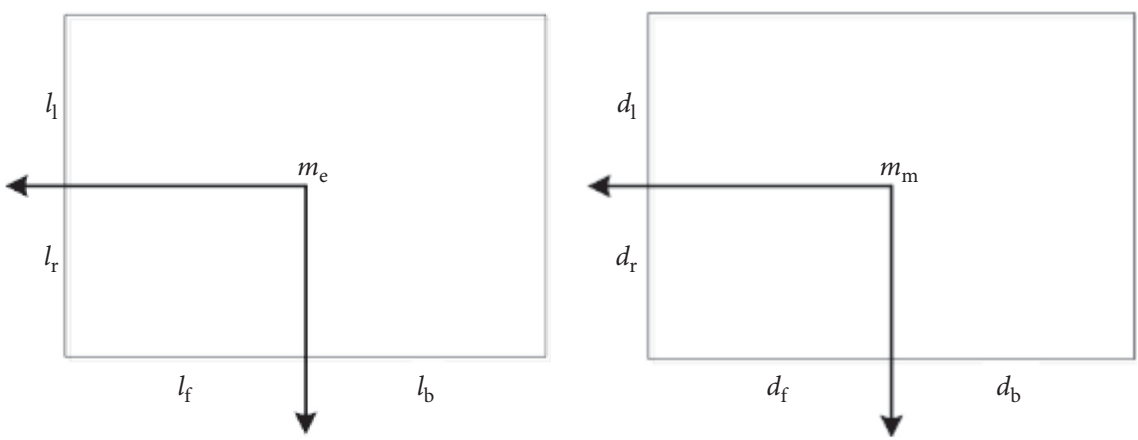

(a)

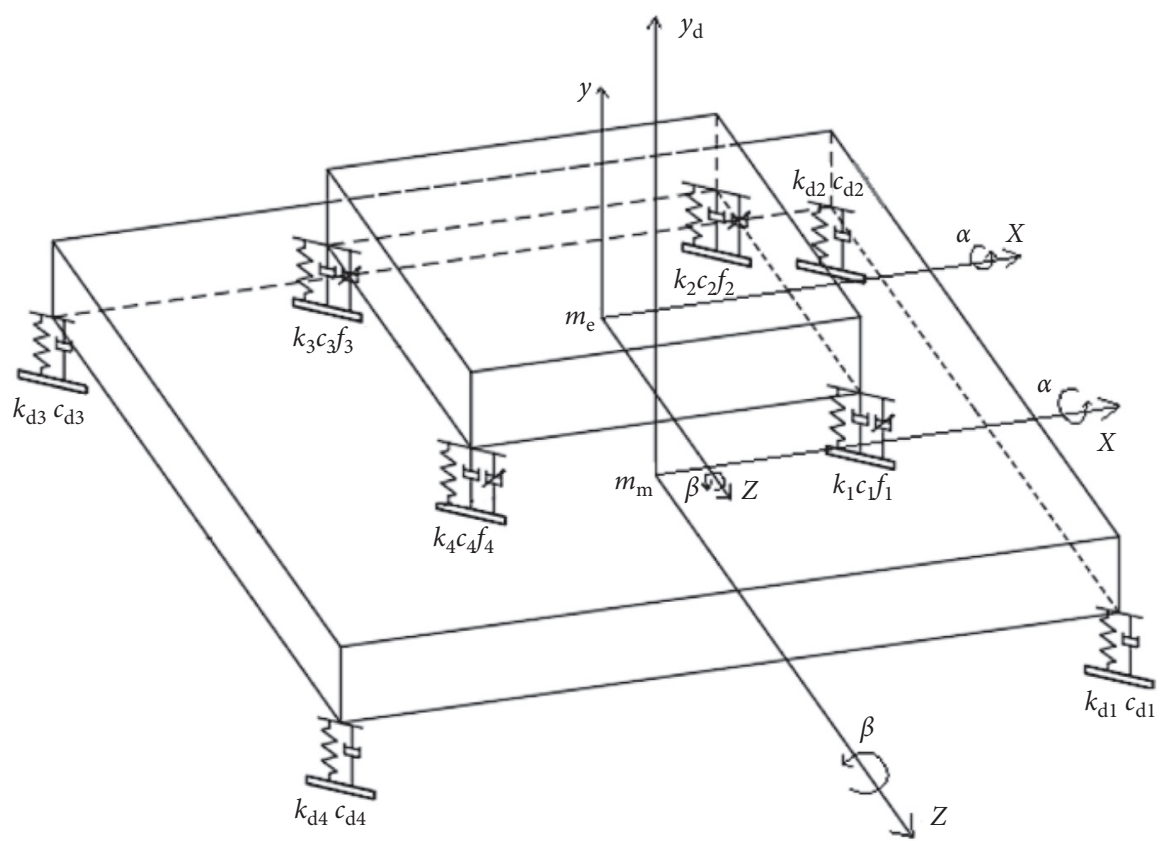

(b)

FIGURE 8: Dynamic model of the semiactive isolation system.

to minimize the force transmitted to the base, we adopt the optimal control for the semiactive isolation system.

4.1. Optimal Control Design. In the optimal control design, the space state equation is used to describe the characteristics of the system:

$$
\left\{\begin{array}{l}
\dot{X}=A \mathbf{X}+B_{1} \mathbf{U}+B_{2} \mathbf{W} \\
\mathbf{Y}=C \mathbf{X}+D \mathbf{U}
\end{array}\right.
$$

The state variables, output variables, and control variables are selected as follows:

$$
\begin{aligned}
& \mathbf{X}=\left[y_{e}, \dot{y}_{e}, \theta_{e}, \dot{\theta}_{e}, \varphi_{e}, \dot{\varphi}_{e}, y_{m}, \dot{y}_{m}, \theta_{m}, \dot{\theta}_{m}, \varphi_{m}, \dot{\varphi}_{m}\right]^{T} \text {, } \\
& \mathbf{Y}=\left[\begin{array}{llll}
y_{1 e} & y_{2 e} & y_{3 e} & y_{4 e}
\end{array}\right]^{T} \text {, } \\
& \mathbf{U}=\left[f_{1}, f_{2}, f_{3}, f_{4}\right]^{T} \text {. }
\end{aligned}
$$

The purpose of semiactive vibration isolation design of marine engines is to reduce the force transmitted to the base as much as possible. In the design process, it is necessary to find the optimal control force of the MR damper. The smaller the control force of the damper, the better the vibration isolation effect. That is to say, high-performance vibration isolation effect can be obtained with lower energy consumption. The quadratic optimal control method is used for semiactive control. The objective function is selected as

$$
\mathbf{J}=\frac{1}{2} \int_{0}^{\infty}\left[q_{1} y_{1 e}^{2}+q_{2} y_{2 e}^{2}+q_{3} y_{3 e}^{2}+q_{4} y_{4 e}^{2}+r u^{2}\right] \mathrm{d} t,
$$

where $q_{1}, q_{2}, q_{3}, q_{4}$, and $r$ are the weighting coefficients, which can be determined according to the requirements of each performance index.

In the form of matrix, the objective function can be expressed as

$$
\mathbf{J}=\frac{1}{2} \int_{0}^{\infty}\left(y^{T} Q y+u^{T} R u\right) \mathrm{d} t
$$

where $R$ is the positive definite matrix, which is the weighting coefficient of control force. $Q$ is the semipositive 
TABLE 2: Simulation parameters of the two-stage isolation system.

\begin{tabular}{lc}
\hline Parameters & Value \\
\hline Mass of engine $(\mathrm{kg})$ & 220 \\
Inertia around the $X$-axis $\left(\mathrm{kg} * \mathrm{~m}^{2}\right)$ & 16 \\
Inertia around the $Z$-axis $\left(\mathrm{kg} * \mathrm{~m}^{2}\right)$ & 12 \\
Mass of intermediate block $(\mathrm{kg})$ & 110 \\
$l_{\mathrm{r}}, l_{1}(\mathrm{~mm})$ & 250 \\
$l_{\mathrm{b}}, l_{\mathrm{f}}(\mathrm{mm})$ & 280 \\
$d_{\mathrm{r}}, d_{1}(\mathrm{~mm})$ & 235 \\
$d_{\mathrm{b}}, d_{\mathrm{f}}(\mathrm{mm})$ & 245 \\
Stiffness of upper isolator $\mathrm{K}(\mathrm{kN} / \mathrm{m})$ & 2400 \\
Stiffness of lower isolator $\mathrm{K}(\mathrm{kN} / \mathrm{m})$ & 3800 \\
Radius of crank $(\mathrm{mm})$ & 50 \\
Ratio of crank radius to connecting rod length $\lambda$ & 0.31 \\
Reciprocating part mass of the piston & 0.85 \\
Speed of the engine $n /(\mathrm{r} / \mathrm{min})$ & $0-3000$ \\
\hline
\end{tabular}

definite matrix. Let $u=-\mathbf{K} x$, where $\mathbf{K}$ is the feedback matrix, which is shown in

$$
\begin{aligned}
u & =-\mathbf{K} x, \\
\mathbf{K} & =R^{-1} B_{1}^{T} P .
\end{aligned}
$$

The symmetric matrix $P$ can be solved from the Riccati algebraic equation:

$$
A^{T} P+P A+Q-P B R^{-1} B^{T} P=0 .
$$

The selection principle of the weighting coefficient is to minimize the displacement of the marine engine and the force transmitted to the base. At the same time, it is necessary to ensure the output of the MR damper is in its extreme range. By repeatedly adjusting the values of the weighting matrices $Q$ and $R$, the weighting coefficient of the optimal control is determined as

$$
\begin{aligned}
& \mathbf{Q}=\left[\begin{array}{ccrc}
1 e 6 & 0 & 0 & 0 \\
0 & 1 e 6 & 0 & 0 \\
0 & 0 & 1 e 6 & 0 \\
0 & 0 & 0 & 1 e 6
\end{array}\right], \\
& R=[1 e-4] .
\end{aligned}
$$

4.2. Simulation Analysis of Response Characteristics. The steady-state response of the engine vibration and the transmission characteristics of the vibration isolation system are mainly analyzed through numerical simulation. The main parameters of the semiactive vibration isolation system are shown in Table 2.

First of all, the natural characteristics of the passive twostage isolation system are calculated when ignoring the system damping. The results show that the vertical natural frequencies of the system appear at $12 \mathrm{~Hz}$ and $20 \mathrm{~Hz}$, respectively. After adding the MR damper, the natural frequencies of the semiactive control system will change slightly due to the existence of damping. In the steady-state simulation analysis, the force transmitted to the base at specific speeds including two resonance speeds and some isolation speeds are shown in Figure 9.

It can be seen that the force transmitted to the base is significantly reduced by using the optimal control compared with the passive isolation system at a given speed. The results show that the isolation effect of optimal control is better than that of passive control. When the rotating speed is equal to $600 \mathrm{r} / \mathrm{min}$ and $1200 \mathrm{r} / \mathrm{min}$, the system is near resonance state, so the transmitted force under the passive isolation is more than the excitation force and the system response is amplified. When optimal control is adopted, the transmitted force of the isolation system in the resonance frequency band is attenuated. This shows the semiactive control has better isolation effect. When the speed continues to increase, both the two vibration isolation measures have excellent isolation effect.

The current required by the MR damper will change with time and speed. At $1200 \mathrm{r} / \mathrm{min}$, we can observe that the proposed methodology required the control of the current (shown in Figure 10), considering the control module of the MR damper in Figure 5. The comparison between the actual and the ideal damping force is shown in Figure 11. The results show that control module of the MR damper can accurately propose the required current.

In order to further analyze the response characteristics of the semiactive system, the force amplitude transmitted to the base at different operating speeds is shown in Figure 12(a). It can be seen that the two peaks of transmitted force appeared at $400 \mathrm{r} / \mathrm{min}$ and $1150 \mathrm{r} / \mathrm{min}$, respectively. Compared with the natural frequency of the undamped system, it is found that peak frequency at the speed of $1150 \mathrm{r} / \mathrm{min}$ is close to the natural frequency of $20 \mathrm{~Hz}$, so the vibration is amplified. The first resonance peak at $12 \mathrm{~Hz}$ moves forward when introducing the MR damper, which is related to the damping of the system.

The force transmissibility at different speeds is shown in Figure 12(b), which is the ratio of the force transmitted to the base to the excitation force. It can be seen that the vibration reduction performance of the semiactive isolation system with optimal control is better than that of the passive isolation system in the whole frequency band. Especially in the case of resonance, the semiactive control of the MR damper 


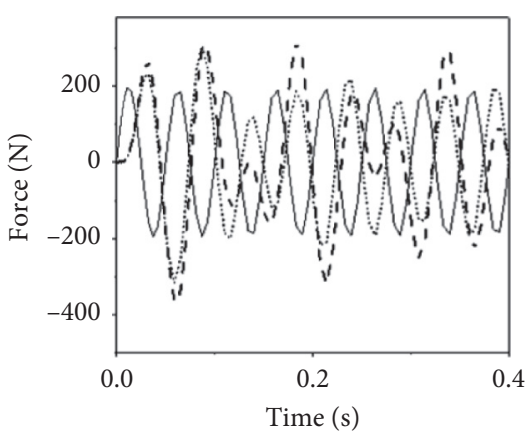

(a)

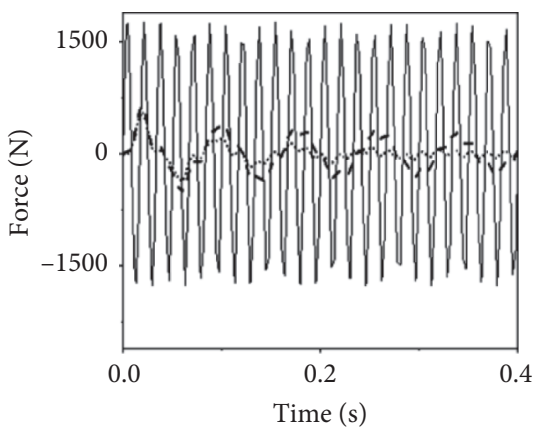

(d)

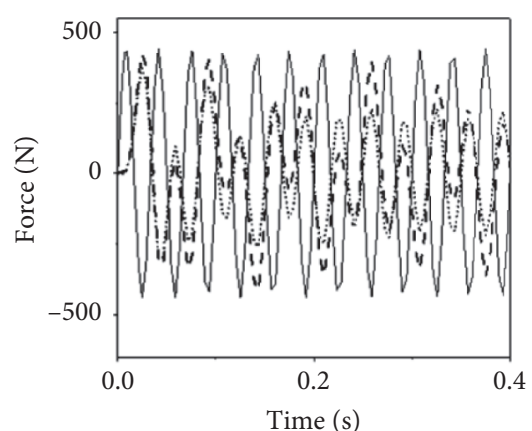

(b)

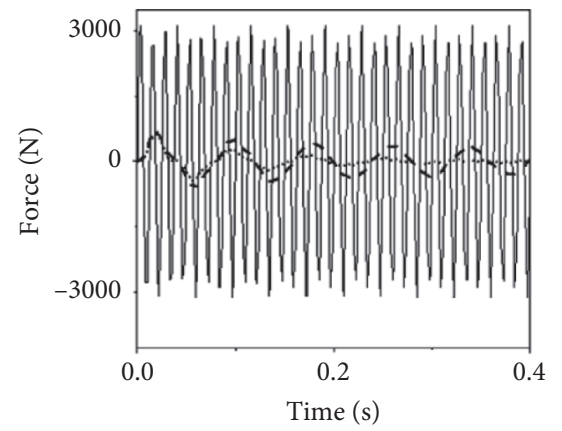

(e)

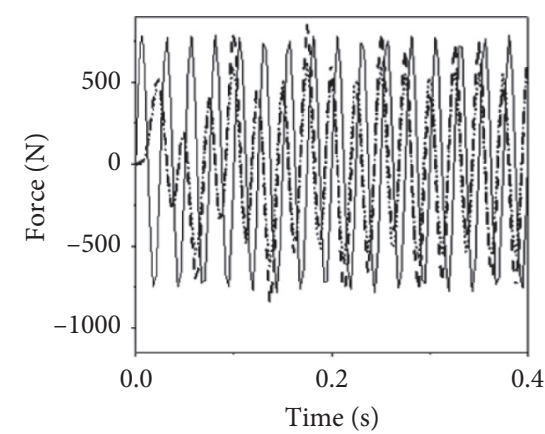

(c)

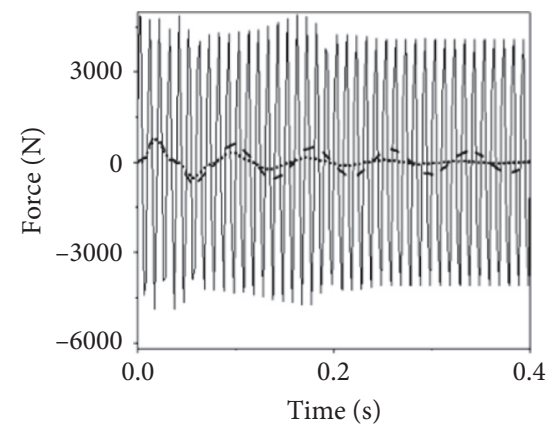

(f)

FIgURE 9: The force transmitted to the base under different control measures. Solid line: excitation force; dashed line: passive isolation; dotted line: optimal control. (a) $r=600 \mathrm{r} / \mathrm{min}$, (b) $r=900 \mathrm{r} / \mathrm{min}$, (c) $r=1200 \mathrm{r} / \mathrm{min}$, (d) $r=1800 \mathrm{r} / \mathrm{min}$, (e) $r=2400 \mathrm{r} / \mathrm{min}$, and (f) $r=3000 \mathrm{r} / \mathrm{min}$.

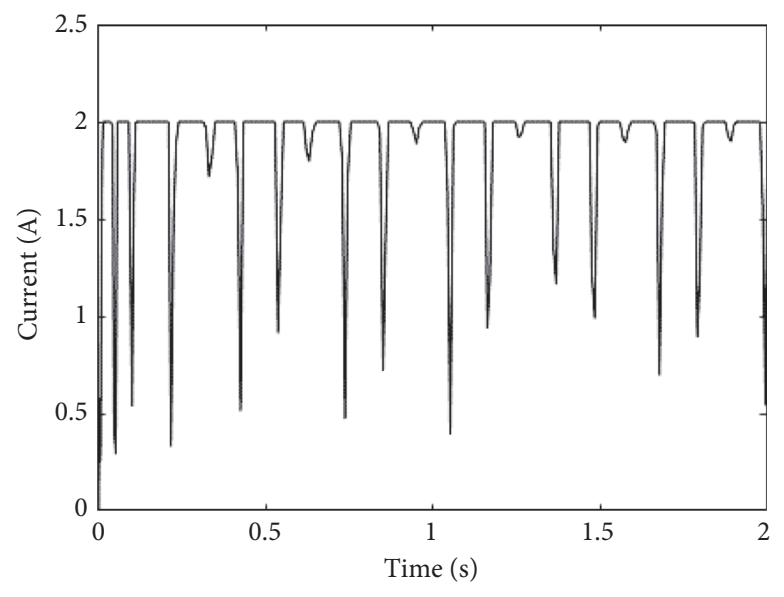

FIgURE 10: Current used to control the semiactive system.

can suppress the resonance peak obviously. At the second resonance frequency, the force transmitted to base by optimal control is less than the excitation force. Near the first resonance frequency in the low-frequency region, the transmitted force is more than the excitation force. Generally speaking, the excitation force of the first natural frequency in low-frequency band is relatively small, so the system response will not be excessive. 


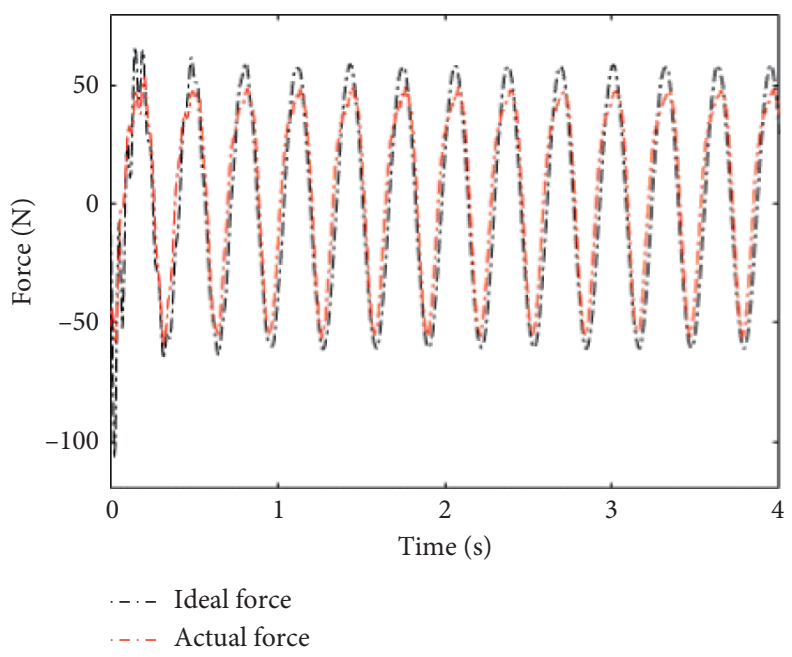

FIgURe 11: Comparison between actual and ideal damping force.

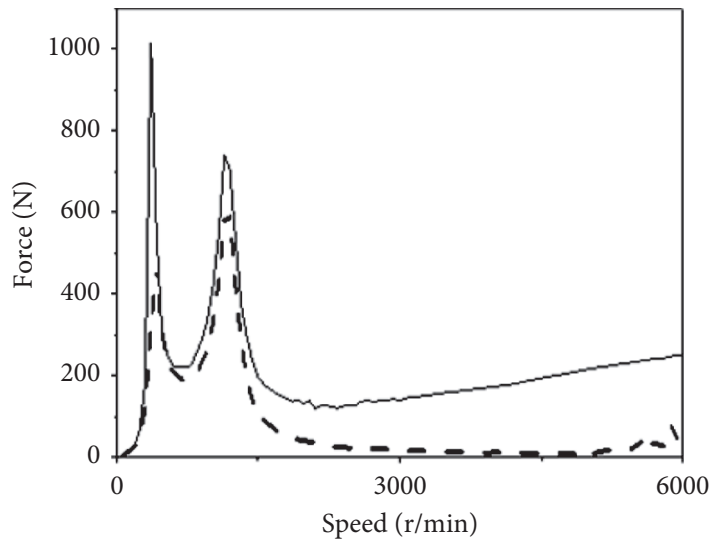

(a)

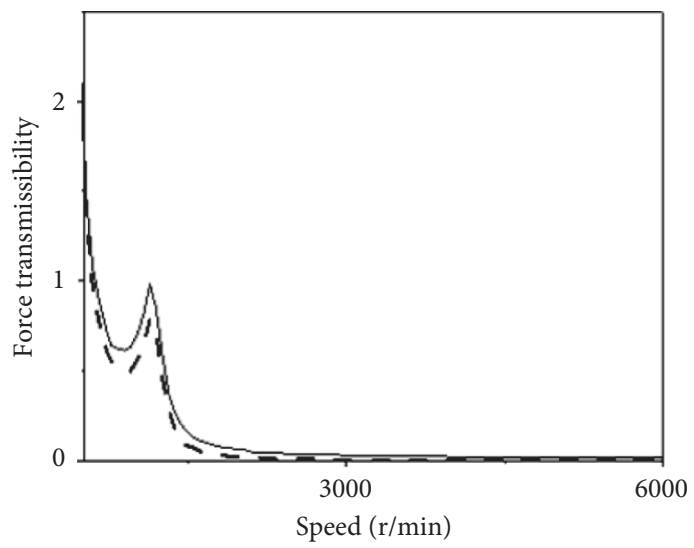

(b)

Figure 12: Force and force transmissibility of the two-stage isolation system. Solid line: passive isolation; dashed line: optimal control. (a) Force/N. (b) Force transmissibility.

\section{Conclusions}

The MR damper is introduced into the two-stage vibration isolation system for marine engines, and its input current is controlled by the control module. The optimal control method is used to study the transmission characteristics of semiactive isolation systems. By analyzing the time-frequency characteristics of the force transmitted to the base, the following conclusions may be obtained:

(1) The forward model of the hyperbolic tangent MR damper is fitted by the least square method, and the error is controlled within $5 \%$. In order to calculate the target control current through the damping force and response, the neural network method optimized by genetic algorithm is used to obtain the inverse model of the damper. The error between the predicted value and the target value is only $2.3 \%$, which indicates that the model has good prediction accuracy.
(2) Based on the hyperbolic tangent forward model and GA-BP inverse model of the MR damper, a control module is established to limit the current of the MR damper between its extreme values, which is used in semiactive optimal control. This can ensure the normal operation of the MR damper.

(3) Within the operating speed range of the marine engine, the vibration isolation effect of the optimal control is better than that of the passive vibration isolation. Moreover, the semiactive vibration isolation measure also significantly reduces force transmissibility in the resonance region.

(4) At present, the controllable output force of the MR damper cannot meet the vibration isolation requirements of a large power engine. The research and development of high-performance MR materials should be conducted. By integrating intelligent control technology and vibration isolation technology of power engines, the semiactive intelligent 
control device suitable for large engines should be developed and designed.

\section{Data Availability}

Data cannot be shared due to data access restrictions.

\section{Conflicts of Interest}

The authors declare that they have no conflicts of interest.

\section{Acknowledgments}

This work was supported by the National Natural Science Foundation of China (51879124) and Natural Science Foundation of Jiangsu Province (BK20191462).

\section{References}

[1] Z. Xia, X. Wang, J. Hou, S. Wei, and Y Fang, "Non-linear dynamic analysis of double-layer semi-active vibration isolation systems using revised Bingham model," Journal of Low Frequency Noise, Vibration and Active Control, vol. 35, no. 1, 2016.

[2] Y.-H. Shin, S.-J. Moon, W.-J. Jung, and S.-R. Bae, "Experimental approach to active mounts using electromagnetic actuator and rubber with consideration of shock resistance for naval shipboard equipment," Shock and Vibration, vol. 2019, no. 8, 15 pages, Article ID 3958359, 2019.

[3] Y. Song, J. Wen, D. Yu, and X. Wen, "Suppression of vibration and noise radiation in a flexible floating raft system using periodic structures," Journal of Vibration and Control, vol. 21, no. 2, pp. 217-228, 2015.

[4] A. M. Tusset and J. M. Balthazar, "On the chaotic suppression of both ideal and non-ideal duffing based vibrating systems using a magnetorheological damper," Differential Equations and Dynamical Systems, vol. 21, 2013.

[5] X. Gu, Y. Yang, Y. Li, J. Li, and B. Samali, "Experimental study of semi-active magnetorheological elastomer base isolation system using optimal neuro fuzzy logic control," Mechanical Systems and Signal Processing, vol. 119, pp. 380-398, 2019.

[6] Y. Yu, S. Royel, Y. Li et al., "Dynamic modeling and control of shear-mode rotational MR damper for mitigating hazard vibration of building structures," Smart Materials and Structures, vol. 29, no. 11, pp. 461-478, 2020.

[7] Y. Li, J. Li, W. Li, and H. Du, "A state-of-the-art review on magnetorheological elastomer devices," Smart Materials and Structures, vol. 23, no. 12, Article ID 123001, 2014.

[8] X. Yuan, T. Tian, H. Ling, T. Qiu, and H. He, "A review on structural development of magnetorheological fluid damper," Shock and Vibration, vol. 2019, Article ID 1498962, 33 pages, 2019.

[9] Y. L. Zhao, Z. D. Xu, and C. Wang, "Wind vibration control of stay cables using magnetorheological dampers under optimal equivalent control algorithm," Journal of Sound and Vibration, vol. 443, pp. 732-747, 2019.

[10] Y. Yu, Y. Li, J. Li et al., "Characterizing nonlinear oscillation behavior of an MRF variable rotational stiffness device," Smart Structures and Systems, vol. 24, no. 3, pp. 303-317, 2019.

[11] S. Zhang, W. Shi, and Z. Chen, "Modeling and parameter identification of MR damper considering excitation characteristics and current," Shock and Vibration, vol. 2021, Article ID 6691650, 17 pages, 2021.
[12] Y. Fang, Y. Zuo, and Z. Xia, "Vibration transmission analysis of nonlinear floating raft isolation system with magnetorheological damper," Journal of Low Frequency Noise, Vibration and Active Control, vol. 37, no. 4, pp. 700-710, 2018.

[13] T. M. Zhou, E. W. Chen, Y.-M. Lu, Z.-S. Liu, and W.-W. Chen, "Modified polynomial model and its verification for a MR damper," Journal of Vibration and Shock, vol. 33, no. 7, pp. 221-226, 2014.

[14] C. Graczykowski and P. K. Pawowski, "Exact physical model of magnetorheological damper," Applied Mathematical Modelling, vol. 47, no. 6, pp. 400-424, 2017.

[15] A. M. Tusset, J. M. Balthazar, and J. L. P. Felix, "On elimination of chaotic behavior in a non-ideal portal frame structural system using both passive and active controls," Journal of Vibration and Control, vol. 19, no. 6, pp. 803-813, 2012.

[16] S. B. Choi, S. K. Lee, and Y. P. Park, "A hysteresis model for the field dependent damping force of a magnetorheological damper," Journal of Sound and Vibration, vol. 245, no. 2, pp. 375-383, 2001.

[17] A. M. Tusset, J. M. Balthazar, V. Piccirillo, and F. Brasil, "On suppression of chaotic motions of a portal frame structure under non-ideal loading using a magneto-rheological damper," Journal of Theoretical and Applied Mechanics, vol. 53, no. 3, pp. 653-664, 2015.

[18] S. Dutta and G. Chakraborty, "Modeling and characterization of a magneto-rheological fluid based damper and analysis of vibration isolation with the damper operating in passive mode," Journal of Sound and Vibration, vol. 353, pp. 96-118, 2015.

[19] X. F. Lin, S. M. Chen, and G. R. Huang, "Vibration control of a seismically-excited structural building with MR dampers based on ICA-LQG," Journal of Vibration and Shock, vol. 37, no. 5, pp. 194-201, 2018.

[20] C. Zhao, "Fuzzy-PID control for semi-active floating raft isolation system," Journal of Ship Mechanics, vol. 21, no. 10, pp. 1291-1297, 2017. 